Research Paper

\title{
Elevated Serum Sialic Acid Levels Predict Prostate Cancer As Well As Bone Metastases
}

\author{
Cong Zhang ${ }^{1 *}$, Lei Yan ${ }^{1 *}$, Hongkai Song2 2 , Zheng Ma1,3, Dongshan Chen ${ }^{1}$, Feilong Yang4, Liang Fang1, Zeyan \\ $\mathrm{Li}^{1}$, Kui Li ${ }^{5}$, Dawei $\mathrm{Li}^{1}{ }^{凶}$, Nengwang $\mathrm{Yu}^{1}$, Hainan $\mathrm{Liu}^{1}$, Zhonghua $\mathrm{Xu}^{1}$ \\ 1. Department of Urology, Qilu Hospital of Shandong University, Wenhuaxi Road 107\#, Jinan, 250012, P.R.China \\ 2. Department of Bone and Soft Tissue Tumor, Shandong Cancer Hospital affiliated to Shandong University, Wenhuaxi Road 440\#, Jinan, 250117, P.R.China \\ 3. Department of Urology, The People's Hospital of Liaocheng, Dongchangxi Road 67\#, Liaocheng, 252000, P.R.China \\ 4. Department of Urology, Peking University Third Hospital, Beijing 100191, China. \\ 5. Department of Urology, The people's Hospital of Yucheng, Kaituo Road 753\#, Dezhou, 251200, P.R.China \\ *: These authors contribute equally to the manuscript. \\ $\triangle$ Corresponding author: Dawei Li, Department of Urology, Qilu Hospital of Shandong University, Wenhuaxi Road 107\#, Jinan, 250012, P.R.China; Tel: \\ +86-531-82166701; Fax: +86-531-82169044; Email: lidaweimd@aliyun.com
}

(c) Ivyspring International Publisher. This is an open access article distributed under the terms of the Creative Commons Attribution (CC BY-NC) license (https://creativecommons.org/licenses/by-nc/4.0/). See http://ivyspring.com/terms for full terms and conditions.

Received: 2018.06.06; Accepted: 2018.11.02; Published: 2019.01.01

\begin{abstract}
Objective: To evaluate the value of serum sialic acid (SA) in diagnosis of benign prostatic hyperplasia $(\mathrm{BPH})$, prostate cancer (PCa), and bone metastases in PCa patients.

Materials and Methods: Data from 540 patients who were newly diagnosed with PCa or BPH between November 2014 and March 2018 were retrospectively collected and analyzed. Pretreatment SA levels were compared across various groups, then, associations between SA levels and clinic parameters of patients were analyzed as well. Univariate and multivariate logistic regression analyses were further used to identify independent associations.

Results: The mean SA levels in patients with PCa were significantly higher than with BPH $(p=0.013)$. Furthermore, PCa patients with bone metastases showed elevated SA levels compared with PCa without bone metastases $(p<0.001)$. A multivariate logistic regression model showed that: SA level > 52.35 $\mathrm{mg} / \mathrm{dL}$ was identified to be independently associated with the diagnosis of $\mathrm{PCa}(\mathrm{HR}=1.645, p=0.036)$, and SA level $>59 \mathrm{mg} / \mathrm{dL}$ was identified to be independent association with the presence of bone metastases in PCa patients (HR $=6.421, p=0.012)$.

Conclusions: Elevated SA level is an independent predictor of prostate cancer as well as its bone metastases. Therefore, SA level may be a promising diagnostic and prognostic biomarker for prostate cancer and bone metastases.
\end{abstract}

Key words: prostate cancer, benign prostatic hyperplasia, bone metastases, serum sialic acid.

\section{Introduction}

Prostate cancer $(\mathrm{PCa})$ is a malignant tumor that originates from the man reproductive system, which is becoming a great detriment to male health. At present, PCa is the second most common diagnosed cancer and ranks the second leading cause of deaths in the USA [1]. In 2014, it was reported that 233,000 patients were diagnosed as PCa in United States, and 29,840 deaths were attributed to it [2]. Although the incidence of PCa in Asian was lower than that in United States and Europe [3], the morbidity and mortality of PCa in China is increasing rapidly with the changing of lifestyle [4]. As shown by data, in 2011, the incidence of PCa in China was the ninth most common malignant tumors, the death rate of PCa in Urban men ranked 9th among male malignant tumors as well [3]. The traditional prostate cancer marker, prostate-specific antigen (PSA), showed prominent contributions in the screening, diagnosis, and treatment of prostate cancer. However, there were also some problems such as high costs, long 
waiting time, and low specificity and sensitivity. Furthermore, PCa was prone to be bone metastases, and a considerable proportion of the patients had been advanced stage once diagnosed. A recent study showed that the survival time of PCa patients with bone metastases was significantly shorter than that without bone metastases [5]. Beyond that, there were great differences in treatment methods and protocols between the two kinds of patients. At present, emission computerized tomography (ECT) is most commonly used in assessment of bone metastases in PCa patients and it is regarded as one of the most effective detection method for bone metastases of patients diagnosed as PCa [6]. However, the examination was expensive and had certain radioactivity. Therefore, ECT was suitable to further confirm the metastases of cancer patients but not appropriate for long-term monitoring of patient's progression.

SA is a generic term for a series of hydroxylated monosaccharide derivatives containing 9 carton atoms, which locates at the methylated non-reduction terminal of glycoproteins and glycolipids [7]. The synthesis of glycolipids on the cell membrance is increased and it is secreted into the blood when cells undergo malignant transformation, as in the following, the concentration of SA is elevated in cancer patients [8]. Though studies had indicated that the level of SA in PCa patients was higher than that in normal population [9], small sample, no further analysis of multiple factors and no validated cut-off value for the PCa were existed in these studies. Beyond that, there was few research on the relationship between SA levels and bone metastases of PCa patients especially involving Asian. Therefore, we investigated the differences of SA level in patients with prostate neoplasia in order to verify its values in the diagnosis of $\mathrm{BPH}, \mathrm{PCa}$, as well as bone metastases in Chinese population, and we further give the optimal cut-off value for SA level.

\section{Materials and methods}

Patients. A retrospective collection of medical records was performed for 540 patients who were newly diagnosed as $\mathrm{PCa}$ or $\mathrm{BPH}$ and treated at the Department of Urology, Qilu Hospital of Shandong University, between November 2014 and March 2018. Among 540 patients, 408 patients were diagnosed as $\mathrm{PCa}$, and 132 patients were diagnosed as BPH. The diagnosis of all patients had been confirmed by the biopsy or postoperative pathology. The inclusion criteria for all patients in this study were as follows:

(1) Diagnosis of PCa or BPH at Qilu hospital of Shandong University between November 2014 and March 2018.
(2) Availability of necessary information, such as pre-treatment blood test records, post-operation pathology results and other general information.

(3) No diagnosis of second cancers.

(4) Not underwent preoperative radiotherapy, chemotherapy, or immunotherapy.

The exclusion criteria were as follows:

(1) Coexisting other malignant tumors or history of any malignant tumors.

(2) Clinical or pathological findings suggest acute or chronic inflammation, such as chronic prostatitis, systemic infection, etc.

(3) Pathological diagnosis of prostatic malignant neoplasm but not adenocarcinoma.

(4) Taking procoagulant or anticoagulant drugs within the past 2 weeks.

(5) Patients with inadequate clinical information.

Date collection. Clinical date including patients' age at the time of diagnosis, lactate dehydrogenase (LDH), alkaline phosphatase (AKP), fibrinogen (FIB), and prostate specific antigen (PSA), pathological characteristics (including pathological grade and stage), prostate volume(PV) and ECT were retrieved from the electronic patient records at Qilu Hospital of Shandong University. Based on the patient's Magnetic Resonance Imaging (MRI) results, the prostate volume was estimated according to the formula of "prostate volume $=$ length $\times$ width $\times$ height $\times 0.52$ " [10]. Pathological grade was evaluated using Gleason system, and pathological stage was assessed in accordance with 2002 TNM classification [11].

$S A$ measurement. Before receiving any clinical interventions, $5 \mathrm{~mL}$ of venous blood was drawn from each patient in the early morning after 12 hours fast. Blood sample were stored in test tubes that containing a clot activator and gel, then clotted naturally at room temperature. Subsequently, samples were centrifuged at $2000 \mathrm{rpm}$ for 10 minutes. The serum was separated to determine the concentration of SA by using The Roche Cobas 8000 automatic analyzer. The normal concentration of SA was defined as $45.6 \mathrm{mg} / \mathrm{dL}-75.4$ $\mathrm{mg} / \mathrm{dL}$.

Statistical analysis. The levels of SA in each group were expressed as mean \pm standard deviation (SD), then the Kolmogorov-Smirnov was adopted to assess whether it obeys normal distribution. Student's t-test was used for normal distribution data, if not, the Mann-Whitney U-test or Kruskal-Wallis H-test was employed. Linear correlations between SA levels and LDH, AKP, FIB, PSA were evaluated as well. The receiver operative characteristic (ROC) was adopted to determine the optimal threshold of SA level for different diagnosis. Univariate and multivariate regression models were constructed to further evaluate the value of SA levels in differentiating 
pathological outcomes, and relevant risk was expressed as hazard ratios (HR) with $95 \%$ confidence interval (CI). All tests were two-tailed and " $p$ " less than 0.05 was regarded as statistically significant. All data were analyzed using the Statistical Package for Social Science version 22.0 (SPSS Inc, Chicago, IL, USA) and GraphPad Prim 6 software (GraphPad Software Inc, San Diego, CA, USA).

\section{Results}

Baseline clinical characteristics of study population. All the patients included in the present study consecutively presented at the Department of Urology, Qilu Hospital of Shandong University. After eliminating unqualified patients according to the exclusion criteria, 540 patients were eligible for inclusion in the finally study. Among those people, 408 were PCa and 132 were BPH. The ages of PCa and $\mathrm{BPH}$ were $68.88 \pm 8.19$ years and $68.11 \pm 8.18$ years respectively $(p=0.368)$ (Table 1$)$. The mean level of SA in the PCa cohort was $56.75 \pm 11.47 \mathrm{mg} / \mathrm{dL}$, which was significantly higher than that in the $\mathrm{BPH}$ patients $(54.05 \pm 9.00 \mathrm{mg} / \mathrm{dL})(p=0.013)$ (Table 1, Fig. 1A).

Table 1. Clinical characteristics of PCa and $\mathrm{BPH}$ patients.

\begin{tabular}{llll}
\hline Characteristics & PCa & BPH & $p$ value \\
\hline Patients (n; \%) & $408(75.6 \%)$ & $132(24.4 \%)$ & \\
Age $(y)$ & $68.88 \pm 8.19$ & $68.11 \pm 8.18$ & $0.368^{*}$ \\
SA (mg/dL) & $56.75 \pm 11.47$ & $54.05 \pm 9.00$ & $0.013^{*}$
\end{tabular}

PCa: prostate cancer; BPH: benign prostatic hyperplasia; $p<0.05$ is considered as statistically significant; $p^{*}$ : Mann-Whitney U-test.

Associations between SA levels and clinicopathological characteristics of $P C a$ patients. The associations between SA levels and clinical characteristics of $408 \mathrm{PCa}$ patients were further evaluated. It was significant that pretreatment $S A$ levels were associated with LDH, AKP, FIB, and PSA (all $p<0.001$ ) (Table 2, Fig. 2A, B, C, D). Although no relationships were shown between SA levels and age as well as PV, it was interested that the SA levels in older patients were lower than that in the younger $(56.40 \pm 10.10 \mathrm{mg} / \mathrm{dL}$ vs $57.06 \pm 12.59 \mathrm{mg} / \mathrm{dL}, p=$ 0.726) (Table 2, Fig. 3A) and SA levels of PCa patients with larger prostate gland were higher than those with smaller prostate gland $(58.00 \pm 10.71 \mathrm{mg} / \mathrm{dL}$ vs $55.18 \pm 10.57 \mathrm{mg} / \mathrm{dL}, p=0.080$ ) (Table 2; Fig. 3B). According to ECT results, 41 PCa patients (10.05\%) were diagnosed with bone metastases, $121 \mathrm{PCa}$ patients $(29.66 \%)$ were without bone metastases and other 59 PCa patients (14.46\%) were suggestive of suspicious bone metastases. The remaining 187 people $(45.83 \%)$ did not perform the examination or lost the results. The mean level of SA in patients with bone metastases was significantly higher than that with suspicious bone metastases or without bone metastases (bone metastases: $69.97 \pm 15.14 \mathrm{mg} / \mathrm{dL}$; suspicious bone metastases: $59.89 \pm 12.24 \mathrm{mg} / \mathrm{dL}$; without bone metastases: $54.58 \pm 9.74 \mathrm{mg} / \mathrm{dL}$, respectively. $\left.P^{a}<0.001\right)$ (Table 2, Fig. 1B). Analysis of the bone metastases and without bone metastases revealed that patients with bone metastases showed elevated SA levels compared to patients without bone metastases $(69.97 \pm 15.14 \mathrm{mg} / \mathrm{dL}$ vs $54.58 \pm 9.74$ $\mathrm{mg} / \mathrm{dL}, p^{b}<0.001$ ) (Table 2, Fig. 1B). Moreover, preoperative SA levels of patients diagnosed as $\mathrm{PCa}$ with advanced pathological stage were higher than that with early pathological stage, but not statistically significant (pT4: $58.16 \pm 13.45 \mathrm{mg} / \mathrm{dL}$; pT3: $55.56 \pm$ $6.24 \mathrm{mg} / \mathrm{dL}$; pT2: $54.10 \pm 8.52 \mathrm{mg} / \mathrm{dL}$, respectively. $p$ $=0.391)$ (Table 1; Fig. 3C). However, when considering pathological grade of PCa patients on the basis of Gleason score(GS), SA levels in men with high grade cancer (GS > 7) were elevated compared to the low grade (GS $\leq 7)(58.34 \pm 13.05 \mathrm{mg} / \mathrm{dL}$ vs $55.11 \pm$ $9.43 \mathrm{mg} / \mathrm{dL} ; p=0.024)$ (Table 1; Fig. 2E).
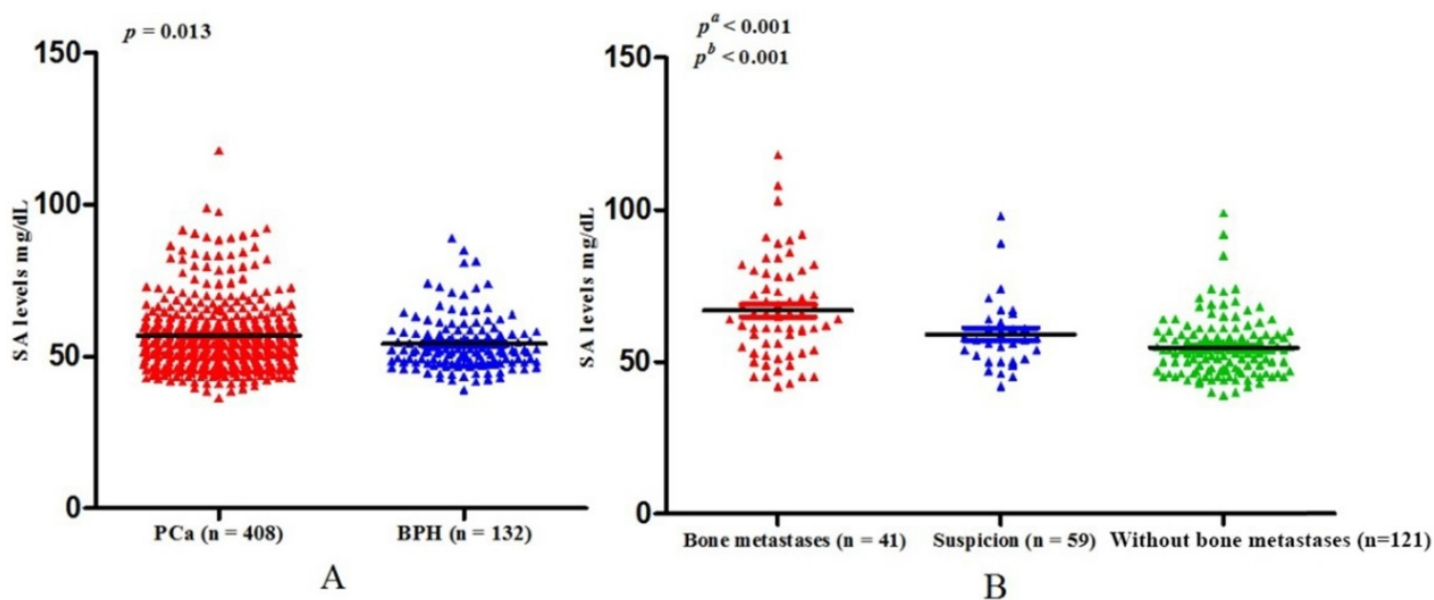

Fig. 1. (A) Comparison of SA levels between PCa and BPH patients; (B) Comparison of SA levels among bone metastases, suspicious bone metastases, and without bone metastases in PCa patients ( $p^{a}$ : Without bone metastases versus suspicion versus bone metastases; $p^{b}$ : Without bone metastases versus bone metastases). 

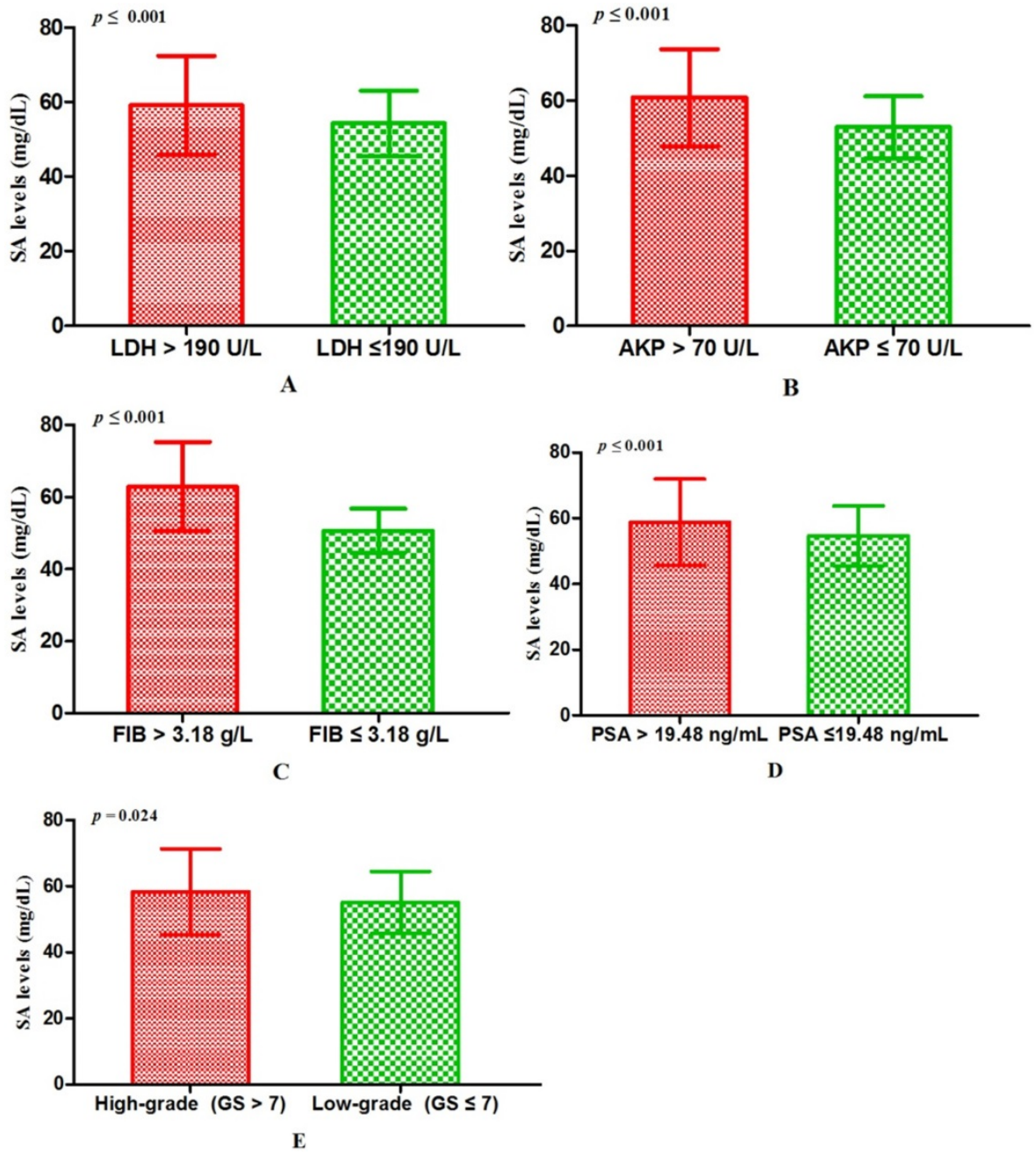

Fig. 2. The comparisons of SA levels in various subgroups of PCa patients. (A) LDH; (B) AKP; (C) FIB; (D) PSA; (E) Gleason score.

Table 2. Correlations between preoperative SA levels and clinicopathological parameters of PCa patients.

\begin{tabular}{|c|c|c|c|}
\hline Characteristics & $\mathrm{n}(\%)$ & $\begin{array}{l}\text { SA levels }(\mathrm{mg} / \mathrm{dL}, \text { Mean } \\
\pm \mathrm{SD})\end{array}$ & $p$ value \\
\hline Patients & $408(100.00)$ & $56.75 \pm 11.47$ & \\
\hline Age $^{a}$ & & & $0.726^{*}$ \\
\hline$\leq 69 y$ & $215(52.70)$ & $57.06 \pm 12.59$ & \\
\hline$>69 y$ & $193(47.30)$ & $56.40 \pm 10.10$ & \\
\hline $\mathbf{L D H}^{\mathbf{a}}$ & & & $<0.001^{*}$ \\
\hline$\leq 190 \mathrm{U} / \mathrm{L}$ & $204(50.00)$ & $54.31 \pm 8.71$ & \\
\hline$>190 \mathrm{U} / \mathrm{L}$ & $204(50.00)$ & $59.19 \pm 13.27$ & \\
\hline AKPa & & & $<0.001^{*}$ \\
\hline$\leq 70 \mathrm{U} / \mathrm{L}$ & $209(51.23)$ & $52.88 \pm 8.24$ & \\
\hline$>70 \mathrm{U} / \mathrm{L}$ & 199 (48.77) & $60.81 \pm 12.92$ & \\
\hline FIB $^{\mathbf{a}}$ & & & $<0.001^{*}$ \\
\hline$\leq 3.18 \mathrm{~g} / \mathrm{L}$ & $205(50.25)$ & $50.68 \pm 6.14$ & \\
\hline$>3.18 \mathrm{~g} / \mathrm{L}$ & $203(49.75)$ & $62.88 \pm 12.33$ & \\
\hline PSA $^{a}$ & & & $<0.001^{*}$ \\
\hline$\leq 19.48 \mathrm{ng} / \mathrm{mL}$ & $204(50.00)$ & $54.63 \pm 9.10$ & \\
\hline$>19.48 \mathrm{ng} / \mathrm{mL}$ & $204(50.00)$ & $58.87 \pm 13.12$ & \\
\hline PVa & & & $0.080^{*}$ \\
\hline$\leq 35.88 \mathrm{~mL}$ & $94(23.04)$ & $55.18 \pm 10.57$ & \\
\hline$>35.88 \mathrm{~mL}$ & $94(23.04)$ & $58.00 \pm 10.71$ & \\
\hline Not performed MRI & $220(53.92)$ & -- & \\
\hline Pathological grade & & & $0.024^{*}$ \\
\hline Low $(\mathrm{GS} \leq 7)$ & $193(47.30)$ & $55.11 \pm 9.43$ & \\
\hline High (GS > 7) & $206(50.49)$ & $58.34 \pm 13.05$ & \\
\hline Missing information & $9(2.21)$ & -- & \\
\hline Pathological stage & & & $0.391^{\#}$ \\
\hline
\end{tabular}

\begin{tabular}{|c|c|c|c|}
\hline Characteristics & $\mathrm{n}(\%)$ & $\begin{array}{l}\text { SA levels }(\mathrm{mg} / \mathrm{dL} \text {, Mean } \\
\pm \mathrm{SD})\end{array}$ & $p$ value \\
\hline pT2 & $102(25.00)$ & $54.10 \pm 8.52$ & \\
\hline pT3 & $16(3.92)$ & $55.56 \pm 6.24$ & \\
\hline pT4 & $34(8.33)$ & $58.16 \pm 13.45$ & \\
\hline biopsy & $256(62.75)$ & -- & \\
\hline \multicolumn{4}{|l|}{ ECT(bone metastases) } \\
\hline $\begin{array}{l}\text { Without bone } \\
\text { metastases }\end{array}$ & $121(29.66)$ & $54.58 \pm 9.74$ & $\begin{array}{l}<0.001^{\text {a }} \\
<0.001^{\text {b }}\end{array}$ \\
\hline Suspicion & 59 (14.46) & $59.89 \pm 12.24$ & \\
\hline Bone metastases & $41(10.05)$ & $69.97 \pm 15.14$ & \\
\hline Not performed ECT & $187(45.83)$ & -- & \\
\hline \multicolumn{4}{|c|}{$\begin{array}{l}\text { PCa: prostate cancer; BPH: benign prostate hyperplasia; PV: prostate volume; GS: } \\
\text { Gleason score; Continuous variables are expressed as mediana; Pathological grade } \\
\text { fall into high grade and low grade using GS; Pathological stage is assessed by } \\
\text { postoperative pathology results (not biopsy) in accordance with } 2002 \text { TNM } \\
\text { classification; } p<0.05 \text { is considered as statistically significant; } p \text { : Without bone } \\
\text { metastases versus bone metastases; } p \text { : Without bone metastases versus suspicion } \\
\text { versus bone metastases; } p^{*}: \text { Mann-Whitney U-test; } p^{*}: \text { Kruskal-Wallis H-test. }\end{array}$} \\
\hline
\end{tabular}

Linear correlation analyses were performed to further evaluate correlations between SA levels and $\mathrm{LDH}, \mathrm{AKP}, \mathrm{FIB}, \mathrm{PSA}$ in PCa patients. AKP, FIB were strongly related to SA levels $(\mathrm{r}=0.427, p=0.000 ; \mathrm{r}=$ 0.694, $p=0.000$, respectively) (Fig. 4B and Fig. 4C). However, correlations between LDH, PSA and SA levels were weak $(r=0.234, p=0.000 ; r=0.205, p=$ 0.000, respectively) (Fig. 4A and Fig. 4D). 
Prognostic value of preoperative SA levels in predicting PCa and bone metastases. The ROC curve for pretreatment SA levels was plotted to assess its predictive value for PCa. The optimal threshold values for SA levels was $>52.35 \mathrm{mg} / \mathrm{dL}$ (PCa vs $\mathrm{BPH})$. The area under the ROC (AUC) was 0.57 (95\% CI 0.52 to 0.63), and the sensitivity, specificity, positive predictive values (PPV), negative predictive values (NPV) were $60.0 \%, 58.6 \%, 81.7 \%$, and $32.1 \%$ respectively (Fig. 5A). According to the ROC curve drawn by the SA levels of patients with bone metastases or without bone metastases, we found that AUC was 0.82 (95\% CI 0.73 to 0.90), and the optimal threshold value was $>59.00 \mathrm{mg} / \mathrm{dL}$. The sensitivity, specificity, PPV, and NPV were $82.9 \%, 78.7 \%, 61.8 \%$, 93.5\% respectively (Fig. 5B).
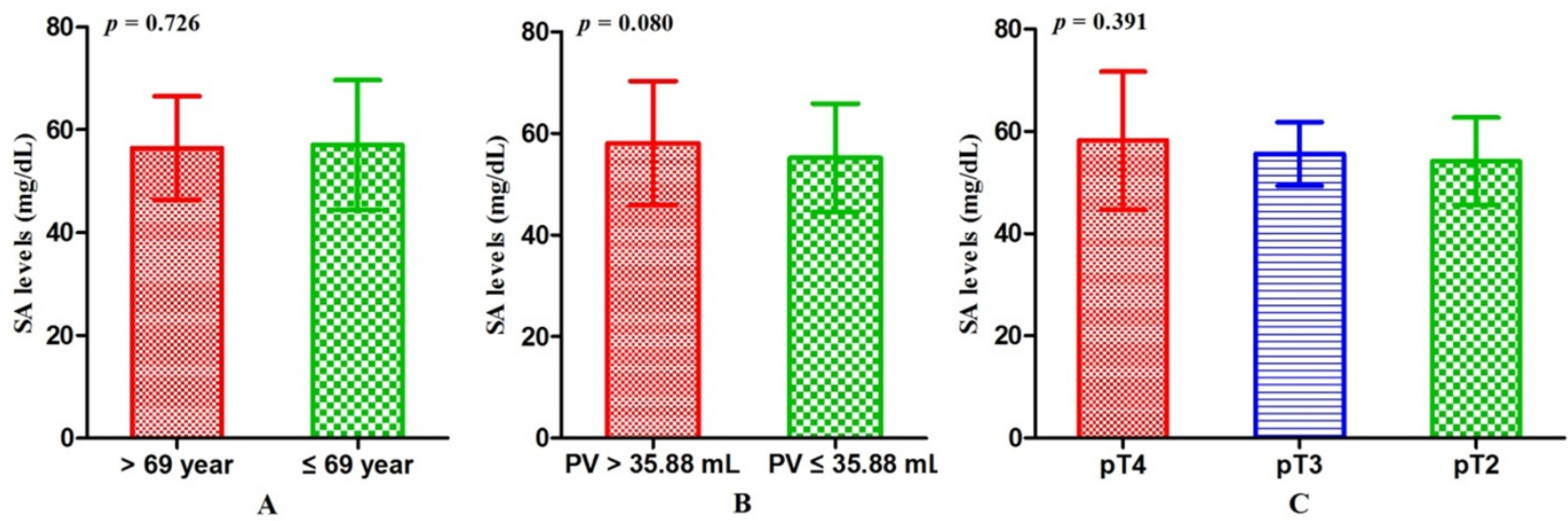

Fig. 3. The comparisons of SA levels within different subgroups of patients diagnosed as PCa. (A) Age; (B) PV; (C) Pathological stage.

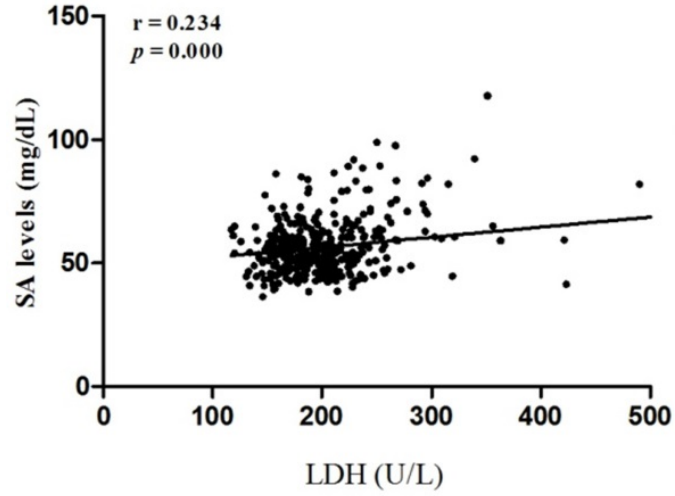

A

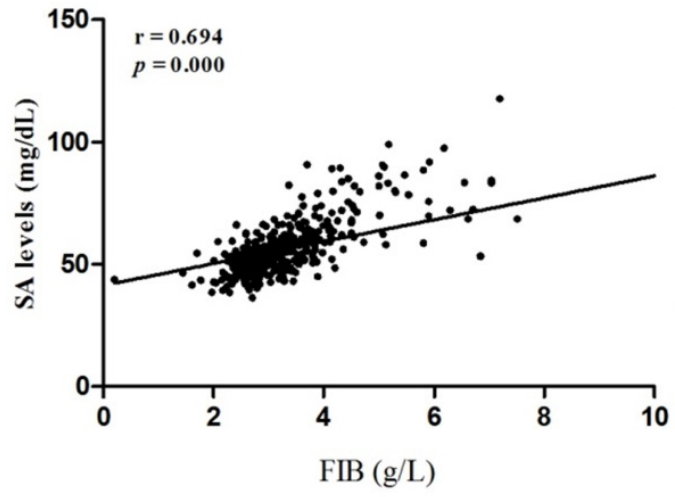

C

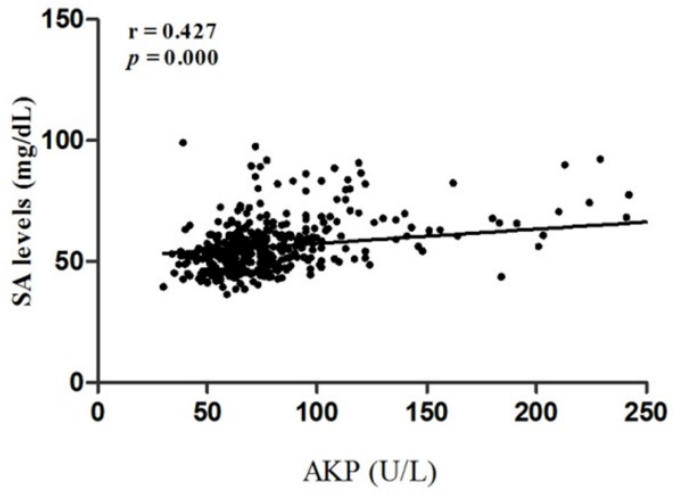

B

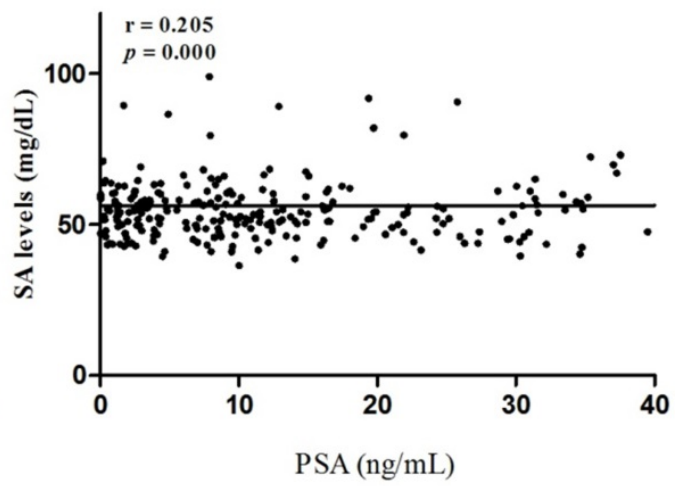

D

Fig. 4. Liner correlations between SA levels and LDH, AKP, FIB, PSA in PCa patients. (A) Liner correlation between SA levels and LDH; (B)Liner correlation between SA levels and AKP; (C) Liner correlation between SA levels and FIB; (D) Liner correlation between SA levels and PSA. 

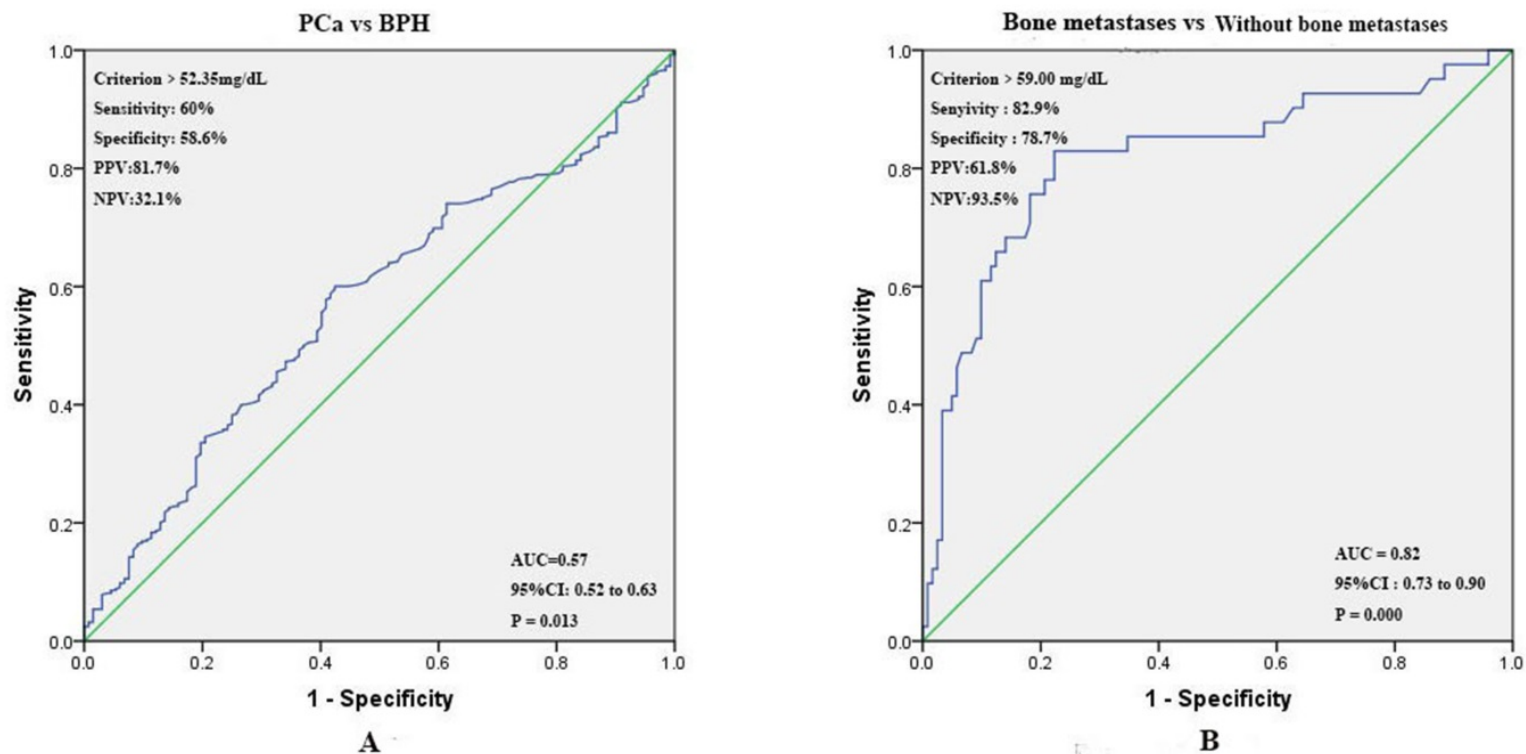

Fig. 5. (A) ROC curves for determination of cut-off value of SA levels regarding prediction of PCa; (B) ROC curves for determination of cut-off value of SA levels regarding prediction of bone metastases in PCa patients.

Table 3. Univariate analysis of preoperative variables prognostic for $\mathrm{PCa}$ and its bone metastases.

\begin{tabular}{|c|c|c|c|c|c|}
\hline \multirow[b]{2}{*}{ Variables } & \multicolumn{2}{|l|}{ PCa vs $\mathrm{BPH}$} & \multicolumn{3}{|c|}{$\begin{array}{l}\text { Bone metastases vs Without bone } \\
\text { metastases }\end{array}$} \\
\hline & HR $(95 \% \mathrm{CI})$ & $\begin{array}{l}p \\
\text { value }\end{array}$ & Variables & HR $(95 \% \mathrm{CI})$ & $\begin{array}{l}p \\
\text { value }\end{array}$ \\
\hline Age & $\begin{array}{l}1.011 \\
(0.987 \sim 1.103)\end{array}$ & 0.351 & Age & $\begin{array}{l}0.999 \\
(0.956 \sim 1.045)\end{array}$ & 0.974 \\
\hline AKP & $\begin{array}{l}1.016 \\
(1.006 \sim 1.025)\end{array}$ & 0.001 & AKP & $\begin{array}{l}1.042 \\
(1.025 \sim 1.058)\end{array}$ & 0.000 \\
\hline LDH & $\begin{array}{l}1.002 \\
(0.999 \sim 1.006)\end{array}$ & 0.230 & $\mathrm{LDH}$ & $\begin{array}{l}1.016 \\
(1.008 \sim 1.025)\end{array}$ & 0.000 \\
\hline FIB & $\begin{array}{l}1.205 \\
(0.974 \sim 1.491)\end{array}$ & 0.086 & FIB & $\begin{array}{l}1.521 \\
(1.132 \sim 2.042)\end{array}$ & 0.005 \\
\hline PSA & $\begin{array}{l}1.058 \\
(1.036 \sim 1.080)\end{array}$ & 0.000 & PSA & $\begin{array}{l}1.006 \\
(1.003 \sim 1.008)\end{array}$ & 0.000 \\
\hline \multirow[t]{2}{*}{ PV } & $\begin{array}{l}0.990 \\
(0.985 \sim 0.995)\end{array}$ & 0.000 & PV & $\begin{array}{l}1.000 \\
(0.996 \sim 1.003)\end{array}$ & 0.788 \\
\hline & & & $\begin{array}{l}\text { Pathological } \\
\text { grade } \\
\text { High vs Low }\end{array}$ & $\begin{array}{l}4.904 \\
(2.076 \sim 11.582)\end{array}$ & 0.000 \\
\hline $\mathrm{SA}(\mathrm{mg} / \mathrm{dL})$ & & & $\mathrm{SA}(\mathrm{mg} / \mathrm{dL})$ & & \\
\hline $\begin{array}{l}>52.35^{*} \text { vs } \leq \\
52.35^{*}\end{array}$ & $\begin{array}{l}2.040 \\
(1.370 \sim 3.037)\end{array}$ & 0.000 & $\begin{array}{l}>52.35^{*} \text { vs } \leq \\
52.35^{*}\end{array}$ & $\begin{array}{l}5.246 \\
(1.925 \sim 14.296)\end{array}$ & 0.001 \\
\hline$>59 \#$ vs $\leq 59 \#$ & $\begin{array}{l}2.061 \\
(1.281 \sim 3.316)\end{array}$ & 0.003 & $>59 \#$ vs $\leq 59 \#$ & $\begin{array}{l}16.910 \\
(6.744 \sim 42.398)\end{array}$ & 0.000 \\
\hline
\end{tabular}

PCa: prostate cancer; $\mathrm{BPH}$ : benign prostate hyperplasia; $\mathrm{LDH}$ : lactate dehydrogenase; AKP: alkaline phosphatase; FIB: fibrinogen; PSA: prostate specific antigen; PV: prostate volume; HR: hazard ratio; Pathological grade: high (Gleason score > 7); low (Gleason score $\leq 7$ ); $\mathrm{SA}^{*}$ : cut-off value of SA levels regarding

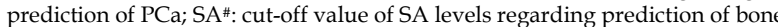
metastases. $p<0.05$ is considered as statistically significant; $95 \%$ CI: $95 \%$ confidence interval.

Logistic regression analysis was constructed to further analyze the clinical impact of pretreatment SA levels in the diagnosis of PCa and bone metastases. In the univariate analysis, elevated SA levels significantly predicted poor diagnostic outcomes, containing PCa and bone metastases (all $p<0.05$ ) (Table 3). In addition, elevated FIB levels and high pathological grade were significantly associated with the diagnosis of bone metastase (FIB: HR=1.521, $p=$ 0.005 ; high grade: $\mathrm{HR}=4.904, p=0.000$, respectively)
(Table 3). Furthermore, we found that the conventional screening biomark, PSA, did not show significant risk to both $\mathrm{PCa}$ and bone metastases (HR: 1.058, $p=0.000$; HR: 1.006, $p=0.000$, respectively) (Table 3). There were insignificant association between worse outcomes and other index (Table 3). Then, AKP, LDH, FIB, pathological grade, and SA were further included in the subsequent multivariate analysis. We find that $\mathrm{SA}>52.35 \mathrm{mg} / \mathrm{dL}$ remained an independent risk for PCa $(\mathrm{HR}=1.645, p=0.036)$ (Table 4). SA > $59 \mathrm{mg} / \mathrm{L}$ and high pathological grade continued to be strong factors related to bone metastases (SA: $\mathrm{HR}=6.421, p=0.012$; high grade: $\mathrm{HR}$ $=19.774, p=0.005$, respectively) (Table 4 ). However, FIB did not show any significant correlation with bone metastases in multivariate analysis.

Table 4. Multivariate analysis of preoperative variables prognostic for PCa and its bone metastases.

\begin{tabular}{|c|c|c|c|c|c|}
\hline & PCa vs BPH & & $\begin{array}{l}\text { Bone metasta } \\
\text { metastases }\end{array}$ & s vs Without bone & \\
\hline Variables & HR $(95 \% \mathrm{CI})$ & $\begin{array}{l}p \\
\text { value }\end{array}$ & Variables & HR $(95 \% \mathrm{CI})$ & $\begin{array}{l}p \\
\text { value }\end{array}$ \\
\hline AKP & $\begin{array}{l}1.010 \\
(0.999 \sim 1.022)\end{array}$ & 0.069 & AKP & $1.046(1.021 \sim 1.072)$ & 0.000 \\
\hline $\mathrm{LDH}$ & $\begin{array}{l}0.997 \\
(0.993 \sim 1.001)\end{array}$ & 0.183 & $\mathrm{LDH}$ & $1.008(0.995 \sim 1.022)$ & 0.215 \\
\hline FIB & $\begin{array}{l}0.912 \\
(0.732 \sim 1.136)\end{array}$ & 0.411 & FIB & $0.738(0.388 \sim 1.404)$ & 0.354 \\
\hline \multirow[t]{2}{*}{ PSA } & $\begin{array}{l}1.059 \\
(1.037 \sim 1.082)\end{array}$ & 0.000 & PSA & 1.005 (1.002 1.009) & 0.006 \\
\hline & & & $\begin{array}{l}\text { Pathological } \\
\text { grade } \\
\text { High vs Low }\end{array}$ & $\begin{array}{l}19.774 \\
(2.460 \sim 158.925)\end{array}$ & 0.005 \\
\hline $\mathrm{SA}(\mathrm{mg} / \mathrm{dL})$ & & & $\mathrm{SA}(\mathrm{mg} / \mathrm{dL})$ & & \\
\hline $\begin{array}{l}>52.35 \text { vs } \leq \\
52.35\end{array}$ & $\begin{array}{l}1.645 \\
(1.033 \sim 3.316)\end{array}$ & 0.036 & $>59$ vs $\leq 59$ & $\begin{array}{l}6.421 \\
(1.502 \sim 27.449)\end{array}$ & 0.012 \\
\hline
\end{tabular}

PCa: prostate cancer; $\mathrm{BPH}$ : benign prostate hyperplasia; $\mathrm{LDH}$ : lactate dehydrogenase; AKP: alkaline phosphatase; FIB: fibrinogen; PSA: prostate specific antigen; PV: prostate volume; HR: hazard ratio; Pathological grade: high (Gleason score $>7$ ); low (Gleason score $\leq 7$ ); $p<0.05$ is considered as statistically significant; $95 \%$ CI: $95 \%$ confidence interval. 


\section{Discussion}

SA is a terminal component of the non-reducing end of carbohydrate chains of glycoproteins and glycolipids [12]. It was mainly expressed in the cell membrance and displayed biological activity by acting as a receptor for biologically activating molecules or mediating intracellular activities, such as recognition, adhesion and antigens [13]. In the early tumor progression, the glycoprotein on the cell membrane would be changed on certain degree, and the activity of glycosyltransferases in the cells would be enhanced [14]. Then, the SA was overexpressed that acted as specific terminal glycan of glycoproteins [15]. Excessive secretion of SA sialylated tumor cells, and helped it evade the monitoring and killing of immune system. In addition, SA could cause damage to the immune system containing lymphocytes and macrophages [16, 17]. Studies had shown that elevated level of SA was significantly associated with pancreatic cancer, colorectal cancer, osteosarcoma, oral squamous cell carcinoma, and other malignancies [18-21]. However, it was worth noting that some studies had observed that SA levels was obviously higher in patients with severe infection or Type II diabetes compared to healthy people [22, 23]. Therefore, when data was enrolled into the present study, any other malignancy, infection, inflammation, diabetes and other correlative factors were eliminated to avoid interference with the finally outcomes.

PCa was one of the most common genitourinary malignancies of men in the world, and it was one of the most common causes of death in male cancers in Western countries [24]. In China, the incidence of PCa was rapidly rising [4]. At present, the most widely used prostate cancer screening index was PSA [25, 26], however, it was difficult to distinguish $\mathrm{PCa}$ and $\mathrm{BPH}$ in some cases. The prostate biopsy was regarded as gold standard that required patients to withstand greater pain, and there was a risk of false negatives for microscopic prostate cancer. Furthermore, PCa was likely to be accompanied by bone metastases. Ramankulov A et al. showed that bone metastases were occurred in more than $70 \%$ of patients with advanced adenocarcinoma, accompanied by an occult process [27]. Whether or not bone metastases occurred was of great significance in tumor prognosis and treatment. Therefore, detection of bone metastases would be considered as an important part of $\mathrm{PCa}$ patients' management plan. The definitive diagnosis of bone metastases was depended on the pathology, but a few studies had shown that the detection rate of bone biopsy was lower than imageological examination in most cases [28]. The diagnostic sensitivity and specificity of ECT were highest in various imaging examinations and it was considered as one of the diagnostic standard for bone metastases in cancer patients at present [29]. However, ECT also had some disadvantages such as high costs, radiation hazards, and difficulty in widespread carried in primary hospitals. On the contrary, the test of SA had advantages of safety, low cost, convenient implementation and generalization in clinical practice.

In the present study, we analyzed pretreatment SA levels in 540 patients as well as other relevant assay index and clinical characteristics. Similar to Goswami K et al. $[9,30]$, we found that SA levels in patients with $\mathrm{PCa}$ were significantly higher than those with BPH. Next, PCa patients were further grouped according to age, AKP, LDH, FIB, PSA, and PV. It was found that SA levels were closely related to $\mathrm{LDH}$, AKP, FIB, and PSA. Using linear correlation analyses, we found that correlations between AKP, FIB and SA levels were strong, but relations existed in LDH, PSA and SA levels were weak. However, it was consistent with the conclusions drawn by CRrook MA et al.[31], no statistically significant correlation was observed between SA levels and age. Numbers of studies presented that PV could be used as a predictor of worse characteristics and recurrence in PCa patients [32-34], therefore the preoperative MRI results were preformed to estimate the volume of prostate according to " prostate volume $=$ length $\times$ width $\times$ height $\times 0.52 "$. To our knowledge, it was the first study founding that there was no significant correlation between SA levels and PV. Meanwhile, PV had no significant value in the diagnosis of PCa and bone metastases. In addition, we noticed that SA levels were significantly related to pathological grade. With higher pathological grade, the levels of SA were elevated as well. However, there was no significant association between pathological stage and SA levels. Patients were further divided into 3 groups according to results of ECT: without bone metastases, suspicious bone metastases, and bone metastases. The levels of SA were increased gradually among three groups (SA levels in three groups: without bone metastases < suspicious bone metastases < bone metastases). ROC curves were further performed for preoperative SA levels regarding the prediction of $\mathrm{PCa}$ and its bone metastases. The best diagnostic cut-off point with maximum Younden index [35] were $>52.35 \mathrm{mg} / \mathrm{dL}$ (PCa vs BPH), and $>59 \mathrm{mg} / \mathrm{dL}$ (bone metastases vs without bone metastases). The AUC, sensitivity, specificity, PPV, NPV for defining accuracy were also shown in the picture. It was obvious that elevated SA level had high sensitivity and specificity in the diagnosis of bone metastases in PCa patients. SA levels were further incorporated into univariate and multivariate analysis, and the results showed that 
elevated SA levels were significant for diagnosis of PCa and bone metastases. Therefore, elevated SA levels could play a promising role in the diagnosis of PCa and bone metastases in PCa patients.

Still, a few limitations should be noticed in present study. First, because the present study was retrospective, the potential for confounding remained. In addition, all the data were sourced from Qilu Hospital of Shandong University, so limitations may be existed in the general applicability of the results.

\section{Conclusions}

The present study demonstrated that preoperative SA levels in $\mathrm{PCa}$ patients were significantly higher than that in BPH patients, and elevated SA levels were closely associated with bone metastases. This study suggested that SA levels may be a promising biomarker and a reliable predictor for $\mathrm{PCa}$ and its bone metastases.

\section{Abbreviations}

PCa: prostate cancer; $\mathrm{BPH}$ : benign prostatic hyperplasia; SA: serum sialic acid; ECT: emission computerized tomography; MRI: magnetic resonance imaging; LDH: lactate dehydrogenase; AKP: alkaline phosphatase; FIB: fibrinogen; PSA: prostate specific antigen; PV: prostate volume; GS: Gleason score; AUC: the area under the ROC; PPV: positive predictive values; NPV: negative predictive values; ROC: the receiver operative characteristic; HR: hazard ratios; 95\% CI: 95\% confidence interval.

\section{Acknowledgements}

This study was supported by financial grants from the National Natural Science Foundation of China (grant Nos: 81502213 and 81372335) (https://isisn.nsfc.gov.cn/egrantweb/), the Natural Science Foundation of Shandong Province (grant Nos: ZR201709230247 and ZR2015HM046) (http://jihlx .sdstc.gov.cn/STDPMS/ZR/Default.aspx), and the Focused Research and Development Program of Shandong Province (grant Nos: 2016GSF201171 and GG201703180001) (http://jihlx.sdstc.gov.cn/STDPM S/GG/Default.aspx).

\section{Ethical approval}

This was a retrospective study and clinical data were identified before analysis; therefore, ethical approval was not required.

\section{Competing Interests}

The authors have declared that no competing interest exists.

\section{References}

1. Evans-Axelsson S, Timmermand OV, Bjartell A, Strand SE, Elgqvist J. Radioimmunotherapy for Prostate Cancer--Current Status and Future Possibilities. Seminars in nuclear medicine. 2016,46(2):165-79.

2. Siegel R, Ma J, Zou Z, Jemal A. Cancer statistics, 2014. CA: a cancer journal for clinicians. 2014,64(1):9-29.

3. Chen W. Cancer statistics: updated cancer burden in China. Chinese journal of cancer research $=$ Chung-kuo yen cheng yen chiu. 2015,27(1):1.

4. Chen W, Zheng R, Zeng H, Zhang S, He J. Annual report on status of cancer in China, 2011. Chinese journal of cancer research = Chung-kuo yen cheng yen chiu. 2015,27(1):2-12.

5. He J, Zeng ZC, Yang P, Chen B, Jiang W, Du SS. Clinical features and prognostic factors for patients with bone metastases from prostate cancer. Asian journal of andrology. 2012,14(3):505-8.

6. Lein M, Miller K, Wirth M, Weissbach L, May C, Schmidt K, et al. Bone turnover markers as predictive tools for skeletal complications in men with metastatic prostate cancer treated with zoledronic acid. The Prostate. 2009,69(6):624-32.

7. Wickramasinghe S, Medrano JF. Primer on genes encoding enzymes in sialic acid metabolism in mammals. Biochimie. 2011,93(10):1641-6.

8. Cylwik B, Chrostek L, Panasiuk A, Szmitkowski M. Serum total and free sialic acid in patients with chronic liver disease. Clinical chemistry and laboratory medicine. 2010,48(1):137-9.

9. Goswami K, Nandeesha H, Koner BC, Nandakumar DN. A comparative study of serum protein-bound sialic acid in benign and malignant prostatic growth: possible role of oxidative stress in sialic acid homeostasis. Prostate cancer and prostatic diseases. 2007,10(4):356-9.

10. Babaei Jandaghi A, Shakiba M, Nasseh H, Korouji Y, Esmaeili S, Khadem Maboudi AA, et al. Application of bland-altman method in comparing transrectal and transabdominal ultrasonography for estimating prostate volume. Iranian journal of medical sciences. 2015,40(1):34-9.

11. Wittekind C, Compton CC, Greene FL, Sobin LH. TNM residual tumor classification revisited. Cancer. 2002,94(9):2511-6.

12. Yokoyama H, Jensen JS, Jensen T, Deckert T. Serum sialic acid concentration is elevated in IDDM especially in early diabetic nephropathy. Journal of internal medicine. 1995,237(5):519-23.

13. Michalakis K, Ilias I, Triantafyllou A, Polymeris A, Kastriotis I, Chairakaki AD, et al. Detection of prostate cancer by sialic acid level in patients with non-diagnostic levels of prostate-specific antigen. Maturitas. 2012,73(4):325-30.

14. Raval GN, Parekh LJ, Patel DD, Jha FP, Sainger RN, Patel PS. Clinical usefulness of alterations in sialic acid, sialyl transferase and sialoproteins in breast cancer. Indian journal of clinical biochemistry : IJCB. 2004,19(2):60-71.

15. Dadhich M, Prabhu V, Pai VR, D'Souza J, Harish S, Jose M. Serum and salivary sialic acid as a biomarker in oral potentially malignant disorders and oral cancer. Indian journal of cancer. 2014,51(3):214-8.

16. Schauer R. Achievements and challenges of sialic acid research Glycoconjugate journal. 2000,17(7-9):485-99.

17. Yogeeswaran G. Cell surface glycolipids and glycoproteins in malignant transformation. Advances in cancer research. 1983,38:289-350.

18. Gruszewska E, Chrostek L, Cylwik B, Tobolczyk J, Szmitkowski M, Kuklinski A, et al. Serum sialic acid as a marker of pancreatic cancers. Clinical laboratory. 2013,59(7-8):781-8.

19. Sandhu R, Lal H, Kundu ZS, Kharb S. Serum fluoride and sialic acid levels in osteosarcoma. Biological trace element research. 2011,144(1-3):1-5

20. Dhakar N, Astekar M, Jain M, Saawarn S, Saawarn N. Total sialic acid, total protein and total sugar levels in serum and saliva of oral squamous cell carcinoma patients: A case control study. Dental research journal. 2013,10(3):343-7

21. Verazin G, Riley WM, Gregory J, Tautu C, Prorok JJ, Alhadeff JA. Serum sialic acid and carcinoembryonic levels in the detection and monitoring of colorectal cancer. Diseases of the colon and rectum. 1990,33(2):139-42.

22. Rajendiran KS, Ananthanarayanan RH, Satheesh S, Rajappa M. Elevated levels of serum sialic acid and high-sensitivity C-reactive protein: markers of systemic inflammation in patients with chronic heart failure. British journal of biomedical science. 2014,71(1):29-32

23. Ekin S, Meral I, Gunduz H, Mert N. Comparative study of total protein, and total and lipid-associated serum sialic acid levels in patients with type 2 diabetes mellitus. Journal of clinical laboratory analysis. 2003,17(4):124-6.

24. Fu W, Madan E, Yee M, Zhang H. Progress of molecular targeted therapies for prostate cancers. Biochimica et biophysica acta. 2012,1825(2):140-52.

25. Wang MC, Valenzuela LA, Murphy GP, Chu TM. Purification of a human prostate specific antigen. Investigative urology. 1979,17(2):159-63.

26. Oesterling JE, Jacobsen SJ, Klee GG, Pettersson K, Piironen T, Abrahamsson PA, et al. Free, complexed and total serum prostate specific antigen: the establishment of appropriate reference ranges for their concentrations and ratios. J Urol. 1995,154(3):1090-5.

27. Huggins C, Hodges CV. Studies on prostatic cancer: I. The effect of castration, of estrogen and of androgen injection on serum phosphatases in metastatic carcinoma of the prostate. 1941. J Urol. 2002,168(1):9-12.

28. Arredondo SA, Downs TM, Lubeck DP, Pasta DJ, Silva SJ, Wallace KL, et al. Watchful waiting and health related quality of life for patients with localized prostate cancer: data from CaPSURE. J Urol. 2008,179(5 Suppl):S14-8. 
29. Peterson JJ, Kransdorf MJ, O'Connor MI. Diagnosis of occult bone metastases: positron emission tomography. Clinical orthopaedics and related research. 2003(415 Suppl):S120-8.

30. El Melegy NT, Aboulella HA, Abul-Fadl AM, Mohamed NA. Potential biomarkers for differentiation of benign prostatic hyperplasia and prostate cancer. British journal of biomedical science. 2010,67(3):109-12.

31. Crook MA, Tutt P, Pickup JC. Elevated serum sialic acid concentration in NIDDM and its relationship to blood pressure and retinopathy. Diabetes care. 1993,16(1):57-60

32. Briganti A, Chun FK, Suardi N, Gallina A, Walz J, Graefen M, et al. Prostate volume and adverse prostate cancer features: fact not artifact. European journal of cancer. 2007,43(18):2669-77.

33. Freedland SJ, Isaacs WB, Platz EA, Terris MK, Aronson WJ, Amling CL, et al. Prostate size and risk of high-grade, advanced prostate cancer and biochemical progression after radical prostatectomy: a search database study. Journal of clinical oncology : official journal of the American Society of Clinical Oncology. 2005,23(30):7546-54

34. Yashi M, Mizuno T, Yuki H, Masuda A, Kambara T, Betsunoh H, et al. Prostate volume and biopsy tumor length are significant predictors for classical and redefined insignificant cancer on prostatectomy specimens in Japanese men with favorable pathologic features on biopsy. BMC urology. 2014,14:43.

35. Hanley JA, McNeil BJ. The meaning and use of the area under a receiver operating characteristic (ROC) curve. Radiology. 1982,143(1):29-36. 